\title{
Özgün araştırma makalesi \\ Farklı yüzey aktif maddeleri ilave edilmiş EDTA solüsyonlarının epoksi rezin içerikli kanal patının dentine bağlanma dayanımı üzerine etkisi: ex vivo
}

\author{
Mehmet Burak Güneşer, ${ }^{*}$ Seyit Bilal Özdemir, \\ Dilara Arslan, Asiye Nur Dinçer \\ Endodonti Anabilim Dalı, Diş Hekimliği Fakültesi, \\ Bezmialem Vakıf Üniversitesi, İstanbul, Türkiye
}

\section{ÖzeT}

AMAÇ: $\mathrm{Bu}$ in vitro çalışmanın amacı EDTA solüsyonuna çeşitli yüzey aktif ajanların ilave edilmesinin epoksi rezin içerikli patın kök kanal dentinine bağlanma dayanımına olan etkisini değerlendirmektir.

GereÇ VE YöNTEM: Altmış adet tek köklü insan alt küçük azı dişinin kronları uzaklaştırıldı. Döner alet sistemi kullanılarak kök kanalları şekillendirildi. Örnekler farklı EDTA (Wizard, Rehber Kimya, İstanbul, Türkiye) solüsyonlarına göre dört farklı gruba $(n=15)$ ayrıldı: Grup 1: \%17 EDTA + \%0.1 benzalkonyum klorür; Grup 2: \%17 EDTA + \%0.1 Tween 80; Grup 3: \%17 EDTA + \%0.1 Triton $X-100$; ve kontrol grubu: yüzey aktif ajan içermeyen \%17 EDTA. EDTA solüsyonlarının yüzey gerilim değerleri tensiometre ile kontrol edildi. Final irrigasyon $1 \mathrm{dk}$ süreyle $5 \mathrm{~mL} \% 5$ sodyum hipoklorit (Wizard) ve ardından atanan gruptaki EDTA solüsyonu ile gerçekleştirildi (5 mL; $1 \mathrm{dk}$ ). Kök kanalları soğuk lateral sıkıştırma yöntemi kullanılarak güta perka ve AH Plus patı (Dentsply DeTrey, Konstanz, Almanya) ile dolduruldu. Kökten horizontal kesitler alınarak, kök kanal dentini ve pat arasındaki bağlanma dayanımı push-out testi ile ölçüldü. Veriler iki yönlü varyans analizi ve post hoc Tukey testleri kullanılarak istatistiksel olarak analiz edildi $(p<0.05)$.

BULGULAR: Yüzey aktif ajanların ilave edildiği EDTA grupları ile kontrol grubu arasında patın bağlanma dayanımı açısından bir fark bulunmadı $(p=0.106)$. Tüm gruplarda koronal ve orta üçlü bölgelerinde push-out bağlanma dayanımları apikal üçlü bölgesinden anlamlı oranda daha yüksek bulundu (sırasıyla $p=0.004$ ve $p=0.002$ ). Koronal ve orta üçlü bölgelerinde ise bağlanma dayanımı açısından istatistiksel olarak anlamlı bir fark gözlenmedi $(p=0.979)$.

Makale gönderiliş tarihi: 08 Aralık 2016; Yayına kabul tarihi: 01 Şubat 2017 İletişim: Dr. Mehmet Burak Güneşer, Bezmialem Vakıf Üniversitesi, Diş Hekimliği Fakültesi, Endodonti Anabilim Dalı, İstanbul, Türkiye;

E-posta: bguneser@hotmail.com
SonUç: EDTA solüsyonuna yüzey aktif ajan ilavesi epoksi rezin içerikli patın bağlanma dayanımını etkilemedi.

ANAHTAR KeLimeLER: EDTA; endodonti; yüzey aktif ajanlar

KaynaK Göstermek İçin: Güneşer MB, Özdemir SB, Arslan D, Dinçer AN. Farklı yüzey aktif maddeleri ilave edilmiş EDTA solüsyonlarının epoksi rezin içerikli kanal patının dentine bağlanma dayanımı üzerine etkisi: ex vivo. Acta Odontol Turc 2017;34(3):86-90

EDiтöR: Güven Kayaoğlu, Gazi Üniversitesi, Ankara, Türkiye

YAYIN HAKKI: (C) 2017 Güneşer ve ark. Bu eserin yayın hakkı Creative Commons Attribution License ile ruhsatlandırılmıştır. Sınırsız kullanım, dağıtım ve her türlü ortamda çoğaltım, yazarlar ve kaynağın belirtilmesi kaydıyla serbesttir.

[Abstract in English is at the end of the manuscript]

\section{Giriş}

Başarılı bir kök kanal tedavisi için kök kanal sisteminden canlı ve nekrotik doku artıkları, debris, bakteri ve toksik ürünlerinin uzaklaştırılabilmesi amacıyla irrigasyon solüsyonlarının kullanımı oldukça önemlidir. ${ }^{1}$ Sodyum hipoklorit $(\mathrm{NaOCl})$ geniş antimikrobiyal aktivitesi, organik dokuları çözebilmesi ve bakteriyel biyofilmi parçalayabilmesi açısından endodontide kullanılan en etkili irrigasyon solüsyonudur. ${ }^{2,3}$ Ancak $\mathrm{NaOCl}$, smear tabakasını tek başına uzaklaştırmakta etkili olmayıp yalnızca bu tabakanın organik kısmına etki edebilmektedir. $^{4}$

Kök yüzeyini örten smear tabakası irrigasyon solüsyonlarının ve kanal içi ilaçların dentin tübüllerine penetrasyonunu engellemektedir. ${ }^{5,6}$ Dolayısıyla kök kanal dolgu materyallerinin de kök yüzeyine adaptasyonunu engellemektedir. ${ }^{7}$ Etilendiamin tetraasetik asit (EDTA) gibi şelasyon ajanlarının kullanımı smear tabakasının inorganik kısmının uzaklaştırılmasını ve böylece kök kanallarının kemomekanik temizliğinin artırımasını sağlamaktadır. ${ }^{7-10}$ Ancak lateral kanallar, isthmuslar ve çeşitli dallanmalardan dolayı oldukça karmaşık olan kök kanal sisteminin tümüyle dezenfeksiyonu oldukça zordur. ${ }^{11}$ 
İrrigasyon solüsyonlarının dentin tübüllerine ve lateral kanallara penetrasyonunun daha iyi sağlanması amacıyla irrigasyon solüsyonlarına çeşitli ilaveler yapılmıştır. ${ }^{1-3,12-15}$ Bazı çalışmalarda irrigasyon solüsyonlarına surfaktan olarak da tanımlanan yüzey gerilimini düşüren yüzey aktif ajanlar ilave edilmiştir. ${ }^{16,17}$

Katyonik bir yüzey aktif ajan olan benzalkonyum klorür (BAK) dentin bağlayıcı sistemlerde, ortodontik rezin simanlarda ve ticari bir EDTA ürünü içerisinde (Salvizol, Pierre Rolland, Merignac, Fransa) yer almaktadır. ${ }^{15}$ Benzer şekilde smear tabakasının uzaklaştırılması amacıyla üretilen Biopure MTAD (Dentsply Tulsa Dental Specialties, Tulsa, OK, ABD) solüsyonu içerisinde non-iyonik yüzey aktif ajanlardan biri olan Tween 80 (T80) bulunmaktadır.7,12 Piyasaya yeni sürülen bir Na$\mathrm{OCl}$ solüsyonu olan ChlorXtra (Vista Dental Products, Racine, WI, ABD) içerisinde ise non-iyonik aktif ajanlardan Triton X-100 (TRX) yer almaktadır.

Daha önce yapılan çalışmalar EDTA solüsyonuna yüzey aktif ajan ilave edilmesinin bu solüsyonun smear tabakasını uzaklaştırma etkinliğine ve dentinden kalsiyum iyonu salımına olumsuz bir etkisinin olmadığını ortaya koymuştur. ${ }^{14,18}$ Öte yandan farklı yüzey aktif ajanların bulunduğu EDTA solüsyonları ile irrigasyon sonrası kanal dolgu patlarının kök dentinine bağlanmasına olan etkisini karşılaştıran bir çalışma bildiğimiz kadarıyla literatürde bulunmamaktadır. Bu in vitro çalışmanın amacı; kök kanallarının çeşitli yüzey aktif ajanları ilave edilmiş EDTA solüsyonları (BAK, T80 ve TRX) ile irrigasyonu sonrasında epoksi rezin içerikli AH Plus patının (Dentsply De Trey, Konstanz, Almanya) push-out bağlanma dayanımına olan etkisini değerlendirmektir.

\section{GeReÇ Ve Yöntem}

Bu çalışma Bezmialem Vakıf Üniversitesi Klinik Araştırmalar Etik Kurulundan (No: 71306642-050.01.04) onay alınarak gerçekleştirilmiştir. Çalışmada protetik ve periodontal sebeplerle çekilmiş çürüksüz 60 adet tek köklü ve tek kanallı insan alt çene küçük azı dişi kullanıldı. Dişlerin meziodistal ve bukkolingual radyografileri incelenerek yalnızca oval kanallı dişler çalışmaya dahil edildi.

Kök yüzeylerinin temizlenmesinden sonra dişler çaIsşmada kullanılana kadar $4{ }^{\circ} \mathrm{C}$ 'de serum fizyolojik solüsyonunda bekletildi. Dişlerin kuronları uzun aksına dik olacak şekilde mine-sement birleşimi hizasında su so- ğutması altında uzaklaştırıldı. Kökler uzunlukları ortalama $16 \mathrm{~mm}$ olacak şekilde standardize edildi. Dişlerin çalışma boyları 15 no'lu K-tipi eğe (Dentsply Maillefer, Ballaigues, İsviçre) ile apikal foramenden $1 \mathrm{~mm}$ kısa olacak şekilde belirlendi. İrrigasyon yapılırken solüsyonun apeksten taşmaması için köklerin apeksi mum ile kapatıldı. Kök kanalları ProTaper Universal eğeleri (Dentsply Maillefer) ile F4 no'lu eğeye kadar şekillendirildi. Her eğe değişiminden önce kök kanalları $3 \mathrm{~mL} \% 5$ $\mathrm{NaOCl}$ (Wizard, Rehber Kimya, İstanbul, Türkiye) ile irrige edildi. Kök kanallarının irrigasyonu tüm çalışma boyunca 27G Endo-Eze Tip (Ultradent, South Jordan, UT, ABD) iğne ucu kullanılarak yapıldı. Final irrigasyon için öncelikle $1 \mathrm{dk}$ süreyle $5 \mathrm{~mL} \% 5 \mathrm{NaOCl}$ ile irrigasyon yapıldı. Ardından dişıler $1 \mathrm{dk}$ boyunca farklı yüzey aktif ajanlar ilave edilmiş EDTA solüsyonları ile irrigasyon yapılmak üzere rastgele 3 deney grubuna ve 1 kontrol grubuna $(n=15)$ ayrıldı.

\section{EDTA solüsyonları}

Çalışmada yeni hazırlanmış ve içeriğinde yüzey aktif ajan bulunmayan \%17 EDTA (Wizard) solüsyonu kullanıldı. EDTA içerisine katılan yüzey aktif ajanlar bir manyetik karıştırıcı yardımıyla oda sıcaklığında $\left(21^{\circ} \mathrm{C}\right)$ homojen bir şekilde karıştırıldı. Deney gruplarındaki tüm EDTA solüsyonlarının yüzey gerilimleri Phoenix 300 tensiometre cihazı (Attension Sigma 700, Biolin Scientific, Espoo, Finlandiya) kullanılarak 'asılı damla yöntemi' ile belirlendi. Çalışmamızın deney grupları, içeriği, kullanılan yüzey aktif ajanların üretici firmaları ve solüsyonların yüzey gerilimi değerleri $(\mathrm{mN} / \mathrm{m})$ Tablo 1 'de verilmiştir.

EDTA solüsyonları ile gerçekleştirilen son yıkamanın ardından kök kanalları kağıt konlar (Diadent, Diamond Dental Industrial, Chongiu City, Güney Kore) ile kurulandı.

\section{Kök kanallarının doldurulması}

Kök kanalları epoksi rezin içerikli bir kök kanal dolgu patı olan AH Plus patı (Dentsply De Trey, Konstanz, Almanya) ve güta perka kullanılarak soğuk lateral sıkıştırma tekniği ile dolduruldu. Çalışma boyunda işaretlenen 0.06 taperli F4 (Dentsply Maillefer) numaralı ana güta perka konunun kanal içerisine uygunluğu tespit edildikten sonra kök kanal patına bulanarak çalışma boyunda yerleştirildi. Kanal dolgusu bir spreader (Mani Sec O, Mani Inc., Tochigi, Japonya) yardımıyla yardımcı güta perkalara yer açılarak soğuk lateral sıkıştırma tekniği

Tablo 1. Çalışmada kullanılan solüsyonlar

\begin{tabular}{llll}
\hline Deney grupları & İçerik & Yüzey aktif ajanın üretici firması & Yüzey gerilim değeri (mN/m) \\
\hline EDTA + BAK & $\% 17$ EDTA ve \%0.1 BAK & Kimetsan, Ankara, Türkiye & $36.1 \pm 0.4$ \\
EDTA + T80 & $\% 17$ EDTA ve \%0.1 T80 & Merck KGaA, Darmstadt, Almanya & $36.0 \pm 0.2$ \\
EDTA + TRX & $\% 17$ EDTA ve \%0.1 TRX & Merck KGaA, Darmstadt, Almanya & $35.8 \pm 0.4$ \\
Kontrol & $\% 17$ EDTA & - & $37.3 \pm 0.8$ \\
\hline
\end{tabular}

BAK: Benzalkonyum klorür, T80: Tween 80, TRX: Triton X-100, EDTA: Etilendiamin tetraasetik asit 
ile tamamlandı. Dişlerin radyografisi alınarak kanal dolgu kalitesi kontrol edildi. Giriş kavitesindeki fazla konlar ısıtılmış bir el aleti yardımıyla uzaklaştırıldı ve bir tepici yardımıyla vertikal yönde sıkıştırıldı. Ardından dişlerin giriş kaviteleri geçici dolgu maddesi (Coltosol F, ColténeWhaledent, Langenau, Almanya) ile kapatıldı. Dişler 2 hafta boyunca $37^{\circ} \mathrm{C}$ ve $\% 100$ nemli ortamda bekletildi.

\section{Push-out testi}

Dişlerin apikal, orta ve koronal üçlüsünden bir elmas separe yardımıyla (IsoMet 1000; Buehler, Lake Bluff, IL, ABD) düşük hızda ve su soğutması altında her bir dişten toplam 6 adet olmak üzere $1 \pm 0.1 \mathrm{~mm}$ kalınlığında horizontal kesitler alındı. Köklerin apikal 2 mm'lik kısmı çalışmaya dahil edilmedi. Alınan her örneğin koronal yüzeyi işaretlendi. Push-out bağlanma dayanımı testi universal test makinesiyle gerçekleştirildi (AGS-X; Shimadzu Corp, Tokyo, Japonya). Kuvvet 1 mm/dk hızında, yönü apikalden koronale olacak şekilde kök kanal dolgusu kanaldan ayrılana kadar uygulandı (Resim 1). Çalışmada apikal ve orta üçlüden alınan örnekler için $0.3 \mathrm{~mm}$ çapında paslanmaz çelikten üretilmiş yuvarlak uçlar kullanılırken koronal üçlüden alınan kesitler için $0.4 \mathrm{~mm}$ çapında uçlar kullanıldı. Farklı çapta uçlar kullanılarak ucun kök kanal duvarlarına teması engellenerek kuvvetin doğrudan kanal dolgu materyaline uygulanması amaçlandı. Elde edilen maksimum kuvvet Newton $(\mathrm{N})$ cinsinden kayıt edildi ve bu değerin kanal dolgu materyalinin yüzey alanına $\left(\mathrm{mm}^{2}\right)$ bölünmesiyle Megapaskal (MPa) cinsinden değerler elde edildi. Her bir örneğin yüzey alanı ise Topçuoğlu ve arkadaşlarının ${ }^{19}$ önerdiği ve uyguladığı yöntem ile hesaplandı.

Bağlanma dayanımı testi sonrası örneklerin kırılma tipleri bir stereomikroskop yardımıyla (SZTP, Olympus Optical Co, Tokyo, Japonya) ×10 büyütmede incelendi. Kırılma başarısızlıkları; adeziv tipi başarısızlık (pat ile kök dentini arasında gerçekleşen kırılma); koheziv tipi başarısızlık (patın kendi içinden gerçekleşen kırılma) ve karışık tip başarısızlık (adeziv ve koheziv başarısızlığın birlikteliği) şeklinde sınıflandırıldı. ${ }^{19}$ Elde edilen verilerin istatistiksel analizi SPSS programında (SPSS Inc, Chicago, IL, ABD) iki yönlü varyans analizi ve post hoc Tukey çoklu karşılaştırma testleri kullanılarak yapıldı. Anlamlılık $\mathrm{p}<0.05$ düzeyinde değerlendirildi.

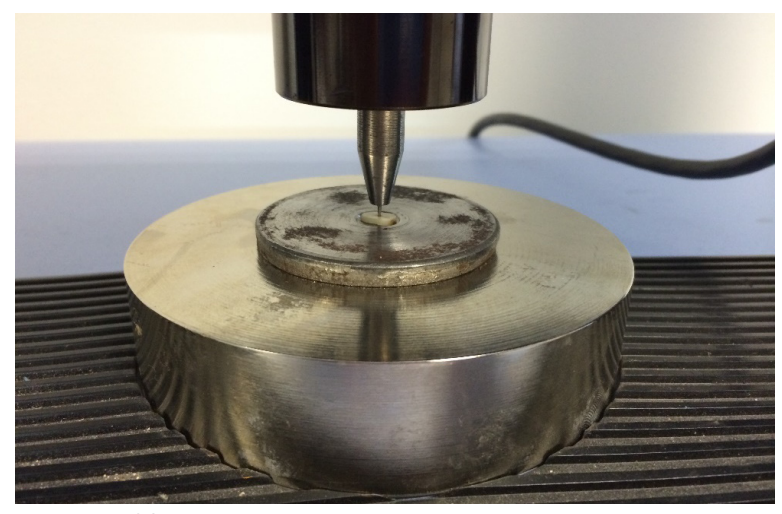

Resim 1. AGS-X cihazı ile güta perka ve kök kanal patına kuvvet uygulaması

\section{BULGULAR}

Grupların ortalama push-out bağlanma değerleri (MPa), standart sapmaları ve istatistiksel olarak önemlilik durumları Tablo 2'de görülmektedir. Yüzey aktif ajan içermeyen \%17 EDTA solüsyonu ile BAK, T80 veya TRX yüzey aktif ajanları ilave edilmiş EDTA solüsyonları arasında push-out bağlanma dayanımı değerleri açısından istatistiksel olarak anlamlı bir farklılık görülmedi $(p=0.106)$. Tüm gruplarda koronal ve orta üçlü bölgelerinde push-out bağlanma dayanımları apikal bölgeden istatistiksel olarak anlamlı oranda daha yüksek bulundu (sırasıyla $p=0.004$ ve $p=0.002$ ). Koronal ve orta üçlü bölgelerinde ise bağlanma dayanımı açısından istatistiksel olarak anlamlı bir fark gözlenmedi $(p=0.979)$.

Bağlanma dayanımı testinin ardından yapılan incelemede tüm gruplarda adeziv, koheziv ve karışık başarısızlık tiplerinin üçü de saptandı. Gözlenen başarısızlık tiplerinin gruplara göre örnek sayısı ve yüzdesel dağılımı Tablo 3'te verilmiştir. Koheziv başarısızılı tüm gruplarda en sık karşılaşılan başarısızıı tipi olarak tespit edildi.

\section{TARTIŞMA}

İrrigasyon solüsyonlarının kök kanal sisteminin tüm bölgelerine ulaştırılarak smear tabakasının etkili bir şekilde uzaklaştırılmasına yönelik pek çok çalışma yapılmıştır. ${ }^{2,4,5,7,8,13,14} \mathrm{Bu}$ amaçla yeni nesil endodontik irrigasyon solüsyonlarına güçlü yüzey aktif ajanlar katılarak solüsyonların hem antimikrobiyal özellikleri hem de kök kanal sisteminin ulaşılması zor alanlara penetrasyonunun artırılması sağlanmıştır.,7,8,12-14 Bu çalışmada farklı yüzey aktif ajanların EDTA solüsyonuna ilavesinin epoksi rezin içerikli kök kanal dolgu patının kök dentinine bağlanma dayanımına olan etkisi karşılaştırıldı.

$\mathrm{NaOCl}$ içine ilave edilen yüzey aktif ajanların $\mathrm{AH}$ Plus patının push-out bağlanma dayanımına etkisinin incelendiği bir çalışmada BAK ve T80 içeren $\mathrm{NaOCl}$ solüsyonlarının push-out bağlanma dayanımına herhangi bir etkisinin olmadığı belirlenmiştir. ${ }^{17}$ Öte yandan TRX içeren $\mathrm{NaOCl}$ ile irrigasyon sonrası push-out bağlanma değerlerinde anlamlı bir artış rapor edilmiştir. ${ }^{17}$ Aynı çalışmada solüsyonların yüzey gerilim değerleri de ölçülmüş ve bu değerlerin birbirine oldukça yakın olmasından dolayı bağlanma değerlerindeki artış ile düşen yüzey gerilimi arasındaki ilişkinin kesin olmadığı belirtilmiştir. ${ }^{17} \mathrm{NaOCl}$ ile irrigasyonla kök kanalı içerisinde oluşan oksijenin miktarının yüzey aktif ajanlardan etkilenebileceği ve böylece rezin içerikli kanal patının dentine bağlanmasında oksijen miktarının rolünün olabileceğini ileri sürülmüştür. ${ }^{20}$ Yüzey aktif ajanlarla ilgili bir başka çalışmada BAK'ın $\mathrm{NaOCl}$ içine katılmasının solüsyonun serbest klor miktarını, sitotoksisitesini ve antimikrobiyal özeliklerini etkilemeden yüzey gerilimini düşürdüğü rapor edilmiştir. ${ }^{15}$ Yine benzer şekilde T80 ve TRX'in NaOCl'nin temas açısını ve böylelikle solüsyonun yüzey gerilimini düşürdüğü belirtilmiştir. ${ }^{15}$ Çalışmamızda push-out bağlanma dayanımı açısından deney grupları 
Tablo 2. Push-out bağlanma dayanımlarının ortalama ve standart sapma değerleri (MPa)

\begin{tabular}{lllll}
\hline & & \multicolumn{2}{c}{ írrigasyon solüsyonları } & \\
Kök kanal bölgeleri & EDTA + BAK & EDTA + T80 & EDTA + TRX & Kontrol (\%17 EDTA) \\
\hline Koronal & $2.61 \pm 1.51^{\mathrm{A}}$ & $2.45 \pm 0.76^{\mathrm{A}}$ & $2.35 \pm 0.99^{\mathrm{A}}$ & $3.02 \pm 1.25^{\mathrm{A}}$ \\
Orta & $2.89 \pm 1.47^{\mathrm{A}}$ & $2.46 \pm 1.04^{\mathrm{A}}$ & $2.99 \pm 1.22^{\mathrm{A}}$ & $2.22 \pm 0.81^{\mathrm{A}}$ \\
Apikal & $2.35 \pm 0.98^{\mathrm{B}}$ & $2.43 \pm 1.07^{\mathrm{B}}$ & $2.28 \pm 1.56^{\mathrm{B}}$ & $1.44 \pm 0.67^{\mathrm{B}}$ \\
\hline
\end{tabular}

Farklı büyük harfler her bir irrigasyon solüsyonu grubunun kök kanalı bölgelerindeki istatistiksel olarak anlamlı farklılı̆ı göstermektedir ( $p<0.05$ ).

BAK: Benzalkonyum klorür, T80: Tween 80, TRX: Triton X-100, EDTA: Etilendiamin tetraasetik asit

Tablo 3. Push-out bağlanma dayanımı testi sonrası gözlenen başarısızlık tiplerinin gruplara göre dağılımı; $n$ (\%)

\begin{tabular}{lllll}
\hline & & \multicolumn{2}{c}{ írrigasyon solüsyonları } \\
Başarısızıı tipi & EDTA + BAK & EDTA + T80 & EDTA + TRX & Kontrol (\%17 EDTA) \\
\hline Adeziv & $24(26.6)$ & $30(33.3)$ & $24(26.6)$ & $24(26.6)$ \\
Koheziv & $36(40)$ & $36(40)$ & $42(46.6)$ & $33(36.6)$ \\
Karışık & $30(33.3)$ & $24(26.6)$ & $24(26.6)$ & $33(36.6)$ \\
\hline
\end{tabular}

BAK: Benzalkonyum klorür, T80: Tween 80, TRX: Triton X-100, EDTA: Etilendiamin tetraasetik asit

arasında önemli bir farkın olmamasına sebep olarak yüzey aktif ajanların EDTA'nın yüzey gerilim değerine önemli bir etkisinin bulunmayışı düşünülebilir. Ancak EDTA ile yüzey aktif ajanlar arasındaki reaksiyonların açıklığa kavuşturulması için ileri çalışmalara intiyaç bulunmaktadır.

Yapılan çalışmalarla EDTA'nın final irrigasyon solüsyonu olarak kullanımasının AH Plus patının push-out bağlanma dayanımında artışa yol açtığı belirtilmiştir.6,12,14 Smear tabakasının kaldırılmasının AH Plus patının kök dentinine bağlanmasında önemli bir rolünün bulunmadığını belirten görüşlerin ${ }^{21}$ yanı sıra smear tabakasının patın kök kanallarına adezyonunu azalttığını ortaya koyan çalışmalar da mevcuttur.6,9,12,14 Patın bağlanmasındaki artışta dentinin yüzey enerjisinde meydana gelen değişikliğin de etkisinin olabileceği düşünülmektedir. ${ }^{12}$ EDTA ile irrigasyonun dentinin ıslanabilirliğini ve yüzey gerilimini azalttığı ve böylece hidrofobik bir pat olan AH Plus'un dentine adezyonunun arttığı ileri sürülmektedir. ${ }^{12}$

Yüzey aktif ajanların EDTA'ya ilave edildiği çalışmalarda ise EDTA'nın temel özelliklerinin çok fazla etkilenmediği görülmektedir. Örneğin yüzey aktif ajan ilavesinin EDTA'nın dentindeki kalsiyuma bağlanma yeteneğine herhangi bir etkisinin olmadığı belirtilmiştir. ${ }^{18}$ Ayrıca içeriğinde farklı yüzey aktif ajanların bulunduğu SmearClear ve QMix ile \%17 EDTA solüsyonunun smear tabakasını uzaklaştırabilme etkinliği birbirine benzer bulunmuştur. $8,13,14$ Çalışmamızda ise yüzey aktif ajan ilavesiyle \%17 EDTA solüsyonunun yüzey gerilim değerlerinin önemli ölçüde değişmediği bulundu. Ancak yüzey aktif ajanların sitotoksisite ve alerjik reaksiyonlar gibi istenmeyen yan etkileri konusunda detaylı bir bilgi bulunmamaktadır. Bu nedenle bu ajanların biyouyumluğu ve klinik performansı konusunda ileri çalışmalara intiyaç bulunmaktadır.

Bu çalışmada çeşitli yüzey aktif ajanların (BAK, T80 ve TRX) ilave edildiği EDTA solüsyonları ile yapılan final irrigasyonun ardından AH Plus patının kök kanalına bağlanma dayanımında anlamlı bir değişiklik olmadığı bulundu. Öte yandan Aranda-Garcia ve ark. ${ }^{14}$ kök kanallarının yüzey aktif ajan içeren SmearClear veya QMix ile irrigasyonu sonrası kök kanal dolgu patının push-out bağlanma değerlerinin \%17 EDTA solüsyonuna göre daha yüksek olduğunu ileri sürmüşlerdir. Ancak elde edilen yüksek push-out bağlanma değerlerinin sebebine yönelik bir değerlendirme yapılmamıştır. Üstelik SmearClear solüsyonu içinde yüzey aktif ajanlardan setrimitin bulunması ve QMix solüsyonu içindeki yüzey aktif ajanın ne olduğu hakkında net bir bilginin olmaması nedeniyle çalışmamız bulgularıyla anlamlı bir karşılaştırma yapılamamaktadır.

Çalışmamızda diğer çalışmaların bulgularına benzer şekilde kökün koronal ve orta üçlü bölgelerinde push-out bağlanma dayanımı apikal üçlü bölgesinden daha yüksek bulunmuştur. ${ }^{9,19}$ Bu duruma sebep olarak koronoapikal yönde dentin tübül yoğunluğunun ve çapının giderek azalması ve buna bağlı olarak apikal bölgede patın tübül içine penetrasyonunun daha düşük olması düşünülebilir. ${ }^{5,22}$ Bu çalışmada ayrıca diğer çalışma bulgularına paralel olarak tüm gruplarda bağlanma dayanımında en sık koheziv başarısızlık gözlenmiştir. Koheziv tip başarısızlık AH Plus'un kök kanal dentinine yüksek adeziv özelliklerinden kaynaklanıyor olabilir.9,19

\section{SONUÇ}

Bu çalışmanın sınırlııkları dahilinde, \%17 EDTA solüsyonuna yüzey aktif ajan ilavesi $\mathrm{AH}$ Plus patının kök dentinine bağlanma dayanımını değiştirmedi. 


\section{TEŞEKKÜR Ve ANMA}

Bu çalışma 23-26 Nisan 2015 tarihlerinde Bükreş, Romanya'da düzenlenen 20. Balkan Stomatological Society (BaSS) Kongresinde sözlü bildiri olarak sunulmuştur.

Çıkar çatışması: Yazarlar bu çalışmayla ilgili herhangi bir çıkar çatışmalarının bulunmadığını bildirmişlerdir.

\section{KAYNAKLAR}

1. Wang Z, Shen Y, Ma J, Haapasalo M. The effect of detergents on the antibacterial activity of disinfecting solutions in dentin. $J$ Endod 2012;38:948-53.

2. Kamburis JJ, Barker TH, Barfield RD, Eleazer PD. Removal of organic debris from bovine dentin shavings. J Endod 2003;29:559-61.

3. Guerreiro-Tanomaru JM, Nascimento CA, Faria-Júnior NB, Graeff MS, Watanabe E, Tanomaru-Filho M. Antibiofilm activity of irrigating solutions associated with cetrimide. Confocal laser scanning microscopy. Int Endod J 2014;47:1058-63.

4. Violich DR, Chandler NP. The smear layer in endodontics - a review. Int Endod J 2010;43:2-15.

5. Lottanti S, Gautschi H, Sener B, Zehnder M. Effects of ethylenediaminetetraacetic, etidronic and peracetic acid irrigation on human root dentine and the smear layer. Int Endod J 2009;42:335-43.

6. Vilanova WV, Carvalho-Junior JR, Alfredo E, Sousa-Neto MD, SilvaSousa YT. Effect of intracanal irrigants on the bond strength of epoxy resin-based and methacrylate resin-based sealers to root canal walls. Int Endod J 2012;45:42-8.

7. Jardine AP, Rosa RA, Santini MF, Wagner M, Só MV, Kuga MC, et al. The effect of final irrigation on the penetrability of an epoxy resinbased sealer into dentinal tubules: a confocal microscopy study. Clin Oral Investig 2016;20:117-23.

8. da Silva LA, Sanguino AC, Rocha CT, Leonardo MR, Silva RA Scanning electron microscopic preliminary study of the efficacy of SmearClear and EDTA for smear layer removal after root canal instrumentation in permanent teeth. J Endod 2008;34:1541-4.

9. Neelakantan P, Varughese AA, Sharma S, Subbarao CV, Zehnder $\mathrm{M}$, De-Deus $\mathrm{G}$. Continuous chelation irrigation improves the adhesion of epoxy resin-based root canal sealer to root dentine. Int Endod $\mathrm{J}$ 2012;45:1097-102.

10. Demiray Kökçü G, Güral A, Altunkaynak B, Kayaoğlu G. Comparison of the smear layer- and debris-removal abilities and the effects on dentinal microhardness of $5 \%$ and $17 \%$ EDTA solutions used as final irrigants: in vitro study. Acta Odontol Turc 2016;33:63-8.

11. Peters LB, Wesselink PR. Periapical healing of endodontically treated teeth in one and two visits obturated in the presence or absence of detectable microorganisms. Int Endod J 2002;35:660-7.

12. Hashem AA, Ghoneim AG, Lutfy RA, Fouda MY. The effect of different irrigating solutions on bond strength of two root canal-filling systems. J Endod 2009;35:537-40.

13. Stojicic S, Shen Y, Qian W, Johnson B, Haapasalo M. Antibacterial and smear layer removal ability of a novel irrigant, QMiX. Int Endod J 2012;45:363-71.

14. Aranda-Garcia AJ, Kuga MC, Vitorino KR, Chávez-Andrade GM, Duarte MA, Bonetti-Filho I, et al. Effect of the root canal final rinse protocols on the debris and smear layer removal and on the push-out strength of an epoxy-based sealer. Microsc Res Tech 2013;76:533-7.

15. Bukiet $F$, Soler $T$, Guivarch $M$, Camps J, Tassery $H$, Cuisinier $F$, et al. Factors affecting the viscosity of sodium hypochlorite and their effect on irrigant flow. Int Endod J 2013;46:954-61.

16. Aslantas EE, Buzoglu HD, Altundasar E, Serper A. Effect of EDTA, sodium hypochlorite, and chlorhexidine gluconate with or without surface modifiers on dentin microhardness. J Endod $2014 ; 40: 876-9$

17. Guneser MB, Arslan D, Dincer AN, Er G. Effect of sodium hypochlorite irrigation with or without surfactants on the bond strength of an epoxy-based sealer to dentin. Clin Oral Investig 2017;21:1259-65.
18. Zehnder M, Schicht O, Sener B, Schmidlin P. Reducing surface tension in endodontic chelator solutions has no effect on their ability to remove calcium from instrumented root canals. J Endod 2005;31:590-2.

19. Topçuoğlu HS, Tuncay Ö, Demirbuga S, Dinçer AN, Arslan H. The effect of different final irrigant activation techniques on the bond strength of an epoxy resin-based endodontic sealer: a preliminary study. J Endod 2014;40:862-6.

20. Rueggeberg FA, Margeson DH. The effect of oxygen inhibition on an unfilled/filled composite system. J Dent Res 1990;69:1652-8.

21. Saleh IM, Ruyter IE, Haapasalo M, Ørstavik D. The effects of dentine pretreatment on the adhesion of root-canal sealers. Int Endod J 2002;35:859-66

22. Tay FR, Gu LS, Schoeffel GJ, Wimmer C, Susin L, Zhang K, et al. Effect of vapor lock on root canal debridement by using a side-vented needle for positive-pressure irrigant delivery. J Endod 2010;36:745-50.

\section{Effect of EDTA with various surface active agents on the bond strength of an epoxy resin-based sealer to dentin: ex vivo}

\begin{abstract}
OBJECTIVE: The aim of this in vitro study was to evaluate the effect of addition of various surface-modifying agents to EDTA solution on the bond strength of an epoxy-based sealer to the root canal dentin.
\end{abstract}

MATERIALS AND MethOD: Sixty single-rooted human mandibular premolars were decoronated and instrumented using rotary system. The specimens were then randomly divided into four groups $(n=15)$ according to irrigation with different EDTA solution (Wizard, Rehber Kimya, Istanbul, Turkey) combinations as follows: Group 1: 17\% EDTA + $0.1 \%$ benzalkonium chloride; Group2: $17 \%$ EDTA + $0.1 \%$ Tween 80; Group 3: 17\% EDTA + 0.1\% Triton X-100 and control group: 17\% EDTA without any surface-modifying agents. Surface tensions of the EDTA solutions were controlled with a tensiometer. Final irrigation was with $5 \mathrm{~mL}$ of $5 \%$ sodium hypochlorite (Wizard) for $1 \mathrm{~min}$, followed by $5 \mathrm{~mL}$ of the mentioned EDTA solution for another minute. Roots were obturated with gutta-percha and AH Plus sealer (Dentsply DeTrey, Konstanz, Germany) using cold lateral compaction technique. Horizontal root sections were obtained, and push-out test was used to measure the bond strength between the root canal dentin and sealer. Data were analyzed using the two-way analysis of variance and post hoc Tukey tests $(p<0.05)$.

RESULTS: The bond strength of sealer in groups irrigated with EDTA in combination with surface modifying agents did not differ from that of the control $(p=0.106)$. The coronal and middle third in all groups exhibited significantly greater bond strength values when compared with the apical third $(p=0.004$ and $p=0.002$, respectively). There was no statistical significant difference between the coronal and the middle thirds $(p=0.979)$.

CONCLUSION: The addition of surface modifying agents to EDTA solution did not affect the bond strength of the epoxy resin-based sealer.

KEYWORDS: EDTA; endodontics; surface active agents 